\title{
Estimating urban heat island effects on near-surface air temperature records of Uccle (Brussels, Belgium): an observational and modeling study
}

\author{
R. Hamdi and H. Van de Vyver \\ Royal Meteorological Institute, 3 Avenue Circulaire, 1180 Brussels, Belgium \\ Received: 27 September 2010 - Revised: 26 January 2011 - Accepted: 2 February 2011 - Published: 7 February 2011

\begin{abstract}
In this letter, the Brussels's urban heat island (UHI) effect on the near-surface air temperature time series of Uccle (the national suburban recording station of the Royal Meteorological Institute of Belgium) was estimated between 1955 and 2006 during the summer months. The UHI of Brussels was estimated using both ground-based weather stations and remote sensing imagery combined with a land surface scheme that includes a state-of-the-art urban parameterization, the Town Energy Balance scheme. Analysis of urban warming based on the remote sensing method reveals that the urban bias on minimum air temperature is rising at a higher rate, 2.5 times (2.85 ground-based observed) more, than on maximum temperature, with a linear trend of $0.15^{\circ} \mathrm{C}\left(0.19^{\circ} \mathrm{C}\right.$ ground-based observed $)$ and $0.06{ }^{\circ} \mathrm{C}\left(0.06^{\circ} \mathrm{C}\right.$ ground-based observed $)$ per decade respectively. The summer-mean urban bias on the mean air temperature is $0.8^{\circ} \mathrm{C}\left(0.9^{\circ} \mathrm{C}\right.$ ground-based observed $)$. The results based on remote sensing imagery are compatible with estimates of urban warming based on weather stations. Therefore, the technique presented in this work is a useful tool in estimating the urban heat island contamination in long time series, countering the drawbacks of an ground-observational approach.
\end{abstract}

\section{Introduction}

It is important to know whether, and to what extent, estimates of global warming trends can be explained by the growth of the urban heat island (UHI) due to increased urbanization. In fact, if observations of near-surface air temperatures in growing cities are used in the assessment of global warming trends, these trends may be overestimated. However, the change in urbanization over time is smaller for a station that originally was established in a densely built-up area than for a station originally installed in a rural or little urbanized environment that has experienced growth. Jones et al. (2008) have shown that near-surface air temperatures in central London and Vienna did not rise relative to rural locations nearby in recent decades. Nevertheless, suburban sites continue to warm relative to nearby rural areas until local urbanization is complete, as shown for London's Heathrow airport by Jones and Lister (2009).

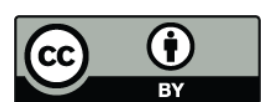

Correspondence to: R. Hamdi

(rafiq.hamdi@oma.be)
The past observational approach compared urban nearsurface air temperature records with records of a rural area. However, selective use of rural sites, requires information (metadata) about the site and its surroundings. Some forms of metadata, such as city population statistics, must be used with care because they may not be representative of the immediate vicinity of the observing site. Also, in situ observations usually suffer from inhomogeneities caused by nonclimatic factors such as changes in observation time, instrumentations, location (altitude and latitude), and other local meteorological features.

With the advent of remote sensing, it has become possible to monitor local urban climate changes associated with land use changes over rapidly expanding urban areas. Specifically, the quantity of impervious surfaces is related to urban growth and urban density (Fricke and Wolff, 2002). The proportion of impervious surfaces has been reported to be a good indicator for the monitoring of the UHI. A positive correlation between the proportion of impervious surfaces and land surface temperatures was identified by Yuan and Bauer (2007) and many earlier studies, also the expansion of the built-up area was found to be the main factor in long-term changes in near-surface air temperatures (Huang et al., 2008; Shouraseni and Yuan, 2009). 
Recently, Hamdi et al. (2009) presents a new technique for estimating effects of increased urbanization on near-surface air temperature trends. Specifically, they combine data from remote sensing imagery and a land surface model including state-of-the-art urban parameterization of Masson (2000), the Town Energy Balance (TEB) scheme. In their study: (i) the land surface model was coupled to a surface boundary layer scheme following the methodology described in Masson and Seity (2009) and evaluated over Basel, Switzerland in Hamdi and Masson (2008), (ii) urbanization was assessed by measuring changes of percent impervious surface areas, and (iii) the land surface scheme was run in a stand-alone mode, coupled to downscaled ERA-40 reanalysis data (Uppala et al., 2005). It should be noted that it was the first time a modeling approach was applied to assess the degree to which background near-surface air temperature trends are amplified by urbanization. This new technique was applied to the Brussels Capital Region (BCR) in Belgium, which has experienced a rapid conversion of agricultural land and native vegetation to buildings and impermeable pavements over the last century (Vanhuysse et al., 2006). However, in their study, no observed data were found to compare the results. Their model-based estimate of urban warming was based on calculating the difference between two model integrations: (i) "the rural" scenario representing a hypothetical situation with no urban areas inside the Brussels Capital Region domain and (ii) the "urban" scenario, which represented the climate in the presence of urban areas using the measured historical changes of surface cover fractions. Recently, a near-surface air temperature record (summer 19552006, minimum $T_{\min }$ and maximum $T_{\max }$ temperature) were found for a rural station far away about $20 \mathrm{~km}$ from Brussels (Van de Vyver, 2010). This station allows the increase of the UHI around Brussels to be determined. Thus, in this work, the UHI effects on the near-surface air temperature time series of Brussels during summer months is estimated using both ground-based weather stations and remote sensing imagery combined with a land surface scheme and the results compared. Therefore, the aim of this letter is to evaluate the technique presented in Hamdi et al. (2009).

\section{Data and model}

\subsection{Study area}

The focus of our study is the Brussels Capital Region (see Fig. 1), centrally located in Belgium, with a size of $161.78 \mathrm{~km}^{2}$ and a registered population of 1031215 on 1 January 2007, estimated by the National Institute of Statistics (INS, 2009). As in the majority of large European cities, it is only during the 19th century that the population strongly increased, exceeding 1 million inhabitants in 2004. There has been a rapid expansion of the capital during the last $50 \mathrm{yr}$. The area covered by the BCR is circular (Fig. 1) with a diam-

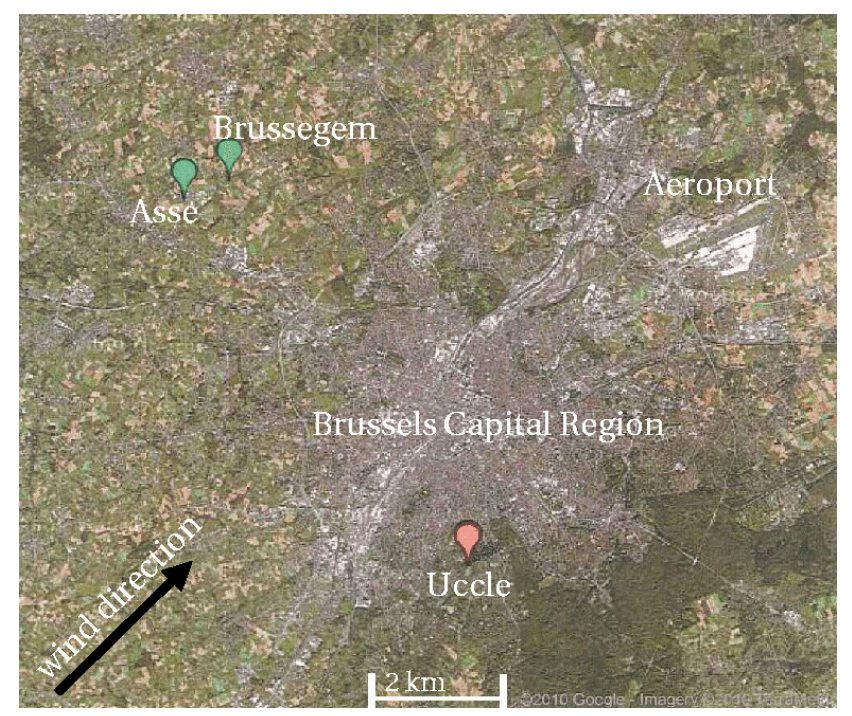

Figure 1. Study area of the Brussels Capital Region. The national recording station of the Royal Meteorological Institute of Belgium (Uccle, urban station) is marked with a red bulb, and rural stations (Asse and Brussegem) with a green bulb. The black arrow presents the direction of the prevailing wind direction in the region.

eter of $12 \mathrm{~km}$ and the effects of urbanization variability dominate the topographic influence (orography is beneath $150 \mathrm{~m}$ ).

\subsection{Meteorological weather station}

The national recording station of the Royal Meteorological Institute (RMI) of Belgium (Uccle, World Meteorological Organization (WMO) code 06447) is situated some $6 \mathrm{~km}$ south of the center of the capital (Fig. 1), in a suburban area $\left(50.80^{\circ} \mathrm{N}, 04.35^{\circ} \mathrm{E}\right)$. The series has been used to monitor climate change in Belgium and is in the world database of land-surface air temperature and in the Global Climate Observing System (GCOS) surface network (Peterson et al., 1997). In order to assess the degree to which the Uccle nearsurface air temperature trends are amplified by urbanization two ground-based meteorological stations, situated $20 \mathrm{~km}$ far away from the center of Brussels and managed by the RMI, are used (see Fig. 1, Table 1). These rural stations are located outside the area influenced by the urban effect of Brussels (Van Weverberg et al., 2008, their Fig. 5) and are not influenced by the SW-prevailing wind direction. Therefore the impact of the city should be negligible. Though the UHI may not be zero in small villages (e.g. Fujibe, 2009), they did not experience a rapid growth during the last century and therefore the urban infrastructure should not have changed its influence on outgoing longwave radiation. 
Table 1. Individual near-surface air temperature series used to estimate the urban warming of the city of Brussels, their observation hours, location and approximate elevation. No missing daily data were found in the datasets of the four climatological series.

\begin{tabular}{lll}
\hline Time span & Observation time & Location (above mean sea level) \\
\hline 1 June 1955-31 August 2006 & Daily max- and minimum & Uccle $(104 \mathrm{~m})$ \\
1 June 1991-31 August 2006 & Daily max- and minimum & Brussegem $(\sim 53 \mathrm{~m})$ \\
1 June 1980-31 August 1990 & Daily max- and minimum & Asse $(\sim 53 \mathrm{~m})$ \\
1 June 1955-31 August 1971 & Daily max- and minimum & Asse $(\sim 53 \mathrm{~m})$ \\
\hline
\end{tabular}

\subsection{Evolution of surface cover fraction}

The evolution of surface cover fractions over the study region were derived from Vanhuysse et al. (2006). This study aims to assess the evolution of the fraction of impervious surfaces in the catchment basins including the BCR since the 1950s date of the acceleration of urban growth linked to widespread use of car as a new mode of transport. Two periods were studied:

1. From 1955 to 1985: Vanhuysse et al. (2006) used the MURBANDY database of topographic maps and areal photos (Fricke and Wollf, 2002) for 1955, 1970, and 1985, to estimate the fraction of impervious surfaces. The results indicate that impervious surfaces have increased from $26 \%$ in 1955 to $39 \%$ in 1985.

2. From 1985 to 2006: Vanhuysse et al. (2006), first, conducted a binary classification of land use (pervious and impervious) based on a very-high-resolution satellite image (UrbOrtho, QuickBird) for 2006. A grid $30 \mathrm{~m}$ resolution was used with the binary classification to extract the percentage of impervious surfaces. A simple regression model between the percentage of impervious surfaces and different spectral variables derived from high-resolution Landsat images was used to estimate the percentage of impervious surfaces for 1993 and 1986 for which only high-resolution images (Landsat Thematic Mapper with $30 \mathrm{~m}$ resolution) are available. The results indicate that impervious surfaces have increased from $39 \%$ in 1985 to $47 \%$ in 2006 (see Fig. 2).

\subsection{Atmospheric data}

The ERA-40 re-analysis (Uppala et al., 2005), produced by the European Centre for Medium-Range Weather Forecasts (ECMWF), covers the period September 1957 to August 2002 with a temporal resolution of $6 \mathrm{~h}$ and a spatial resolution of about $120 \mathrm{~km}$ for Western Europe. In order to increase the spatial resolution over Belgium, a dynamical downscaling method was applied using the numerical weather prediction limited area model ALADIN developed by the ALADIN International Team (1997).

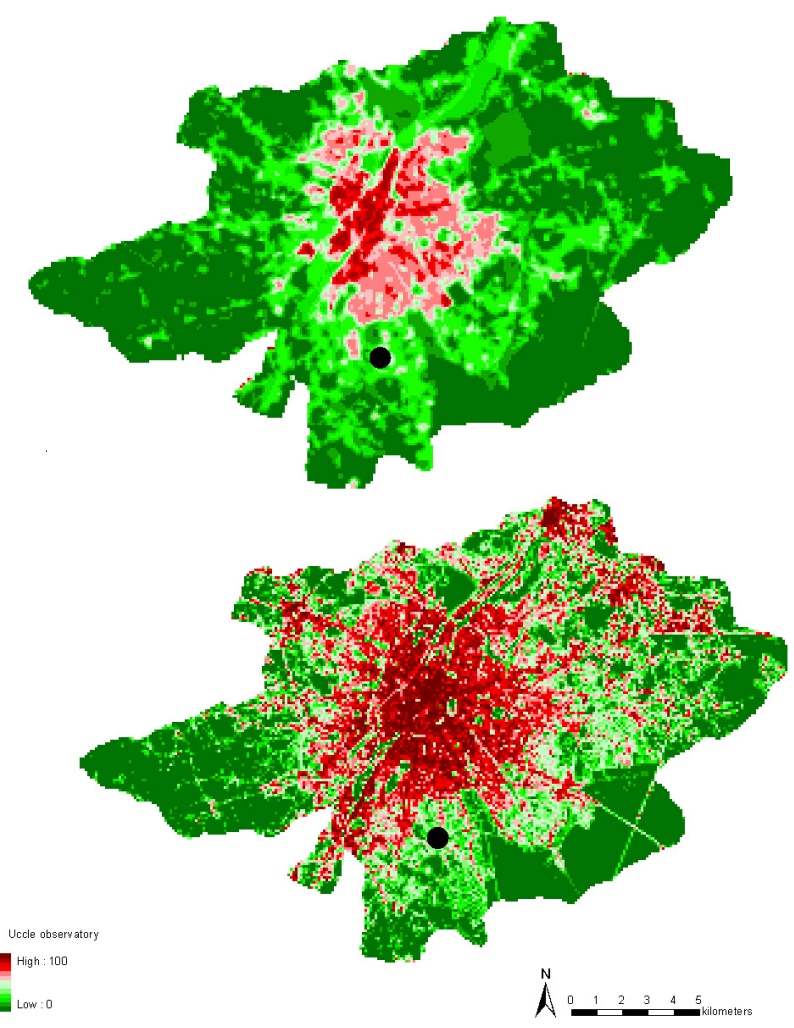

Figure 2. The percentage of impervious surfaces in the catchment basins including the Brussels Capital Region in 1955 (top) and 2006 (bottom). The black dot shows the Uccle observatory location.

A dynamical downscaling to $10 \mathrm{~km}$ resolution over Belgium is performed in two steps: (i) the ALADIN model is coupled to the ERA-40 data and run at a resolution of $40 \mathrm{~km}$ on a domain encompassing most of Western Europe, (ii) these results are then used as initial conditions and lateral boundary conditions for a second downscaling run at $10 \mathrm{~km}$ resolution on a smaller domain over Belgium (see Hamdi et al. (2009) for more details). 


\subsection{Land surface scheme}

We use the offline surface scheme of Météo-France SURFEX (SURFace EXternalisée) (Le Moigne, 2009). In SURFEX, each grid box is made of four adjacent surfaces: nature, urban areas, sea or ocean, and lake. Horizontal interaction does not exist between the different surface area tiles. The coverage of each of these surfaces is known through the global ECOCLIMAP database (Masson et al., 2003). During a model time step (300 s), each surface grid box receives the upper air temperature, specific humidity, wind speed, pressure, total precipitation, long-wave radiation, and short-wave radiation.

For urban surfaces, SURFEX uses the Town Energy Balance (TEB) (Masson, 2000) single-layer urban canopy module which assumes an isotropic array of street canyons. The advantage is that relatively few individual surface energy balance evaluations need to be resolved, radiation interactions are simplified, and therefore computational time is kept low. TEB simulates heat and water exchanges and climate of three generic surfaces (roof, wall, and road), where heat transfers are computed through several layers of materials, generally four. Anthropogenic heat and vapor releases from buildings, vehicles and chimneys can also be added. For vegetated tiles, Noilhan and Planton (1989) Interaction between Soil, Biosphere, and Atmosphere (ISBA) scheme is used. TEB is applied with literature-based surface thermal parameters and observed or simulated atmospheric and radiation data from above roof level. Despite the simplification, offline simulations of TEB have been shown to accurately reproduce surface energy balance, canyon air temperature, and surface temperatures observed in dense urban areas: Vancouver and Mexico City (Masson et al., 2002), Marseille (Lemonsu et al., 2004), Basel (Hamdi and Masson, 2008).

\subsection{Model parameter}

The domain is $10 \mathrm{~km} \times 10 \mathrm{~km}$ over the BCR, centered on the city center of Brussels. This small heterogeneous domain is overlaid on a $1 \mathrm{~km}$ resolution land cover classification provided by the ECOCLIMAP database. The land cover types contained in this domain are then aggregated into 4 tiles (Sea, Lake, Vegetation, and Urban) with the corresponding fractional coverage $(0 \%, 0 \%, 53 \%, 47 \%)$ to be used as the contemporaneous land cover setting. SURFEX is run in one offline single column mode from 1 June 1960 to 31 August 1999 ( $40 \mathrm{yr}$ ), and the forcing variables are derived from the downscaling of the ERA-40 (Sect. 2.4) for the grid point the closest to the BCR. For the vegetation tile, radiative, thermal, and soil properties (albedo, roughness length, emissivity, thermal inertia, leaf area index, etc.) are taken from the ECOCLIMAP database (Masson et al., 2003) and remain fixed through the simulation. For the urban tile, SURFEX uses only one urban land-use class as input. In this study, geometrical, thermal, and radiative properties of roofs, walls, and roads were set to values representing a typi- cal midsize European city (see Table 1 in Hamdi et al., 2009). Another important urban-related aspect is the anthropogenic heat. This term includes all heat emitted by human activities: traffic, release from industry, and release from residential buildings. Over the area presented in this study, releases from buildings have been shown to be the dominant component of the anthropogenic heat (Van Weverberg et al., 2008). In SURFEX, to mimic space heating, a fixed minimum internal building temperature of $19^{\circ} \mathrm{C}$ is specified.

\section{Results and discussion}

\subsection{Urban warming from weather stations}

\subsubsection{Homogeneity testing of the rural series}

In situ observations usually suffer from inhomogeneities caused by nonclimatic factors such as changes in observation time, instrumentation, location (altitude and latitude), and other meteorological features. Without assurance of homogeneity, trend estimates are unreliable and artifacts in longterm observations and rural/urban differences can be introduced and thus may bias the estimate of the UHI. For this reason, the assumption that the three rural subseries could be linked to constitute a reference rural series is tested with respect to homogeneity (details about the homogenization of the time series of Uccle can be found in Demaree et al. (2002)). Following the guidelines described in Wijngaard et al. (2003), the four methods selected to test the departure of homogeneity in the time series are: the standard normal homogeneity test for a single break, the Buishand range test, the Pettitt test, and the Von Neumann ratio test. The first three tests are location-specific tests which means that they are capable of locating the year when a break is likely. The mathematical formulation of the tests and tables with critical values for their test statistics are listed in detail in Wijngaard et al. (2003). The four tests are carried out on two testing variables which are characteristics of the diurnal near-surface air temperature range (DTR): its annual mean (mDTR) and its annual mean of the absolute day-to-day differences (vDTR). In our study, we considered the summer average. A particular test accepts the null hypothesis if and only if the two variables mDTR and vDTR pass the test at the $1 \%$ level. The results of the different tests are grouped into three classes: useful, doubtful, and suspect. The classification depends on the number of tests rejecting the null hypothesis (i.e. no breaks are present) at the $1 \%$ level: useful (at most one test), doubtful (two test), suspect (at least three tests). The critical values for the test statistics are known only for $n=20,30,40,50$, 70,100 . Since our series has $43 \mathrm{yr}$ of data we need to apply the statistical tests to sliding blocks of $40 \mathrm{yr}$.

In Fig. 3, the results of the standard normal homogeneity test and the Pettitt test applied to the mDTR and vDTR series (1955-2002) of the three rural subseries are shown. While the results of the standard normal homogeneity test 

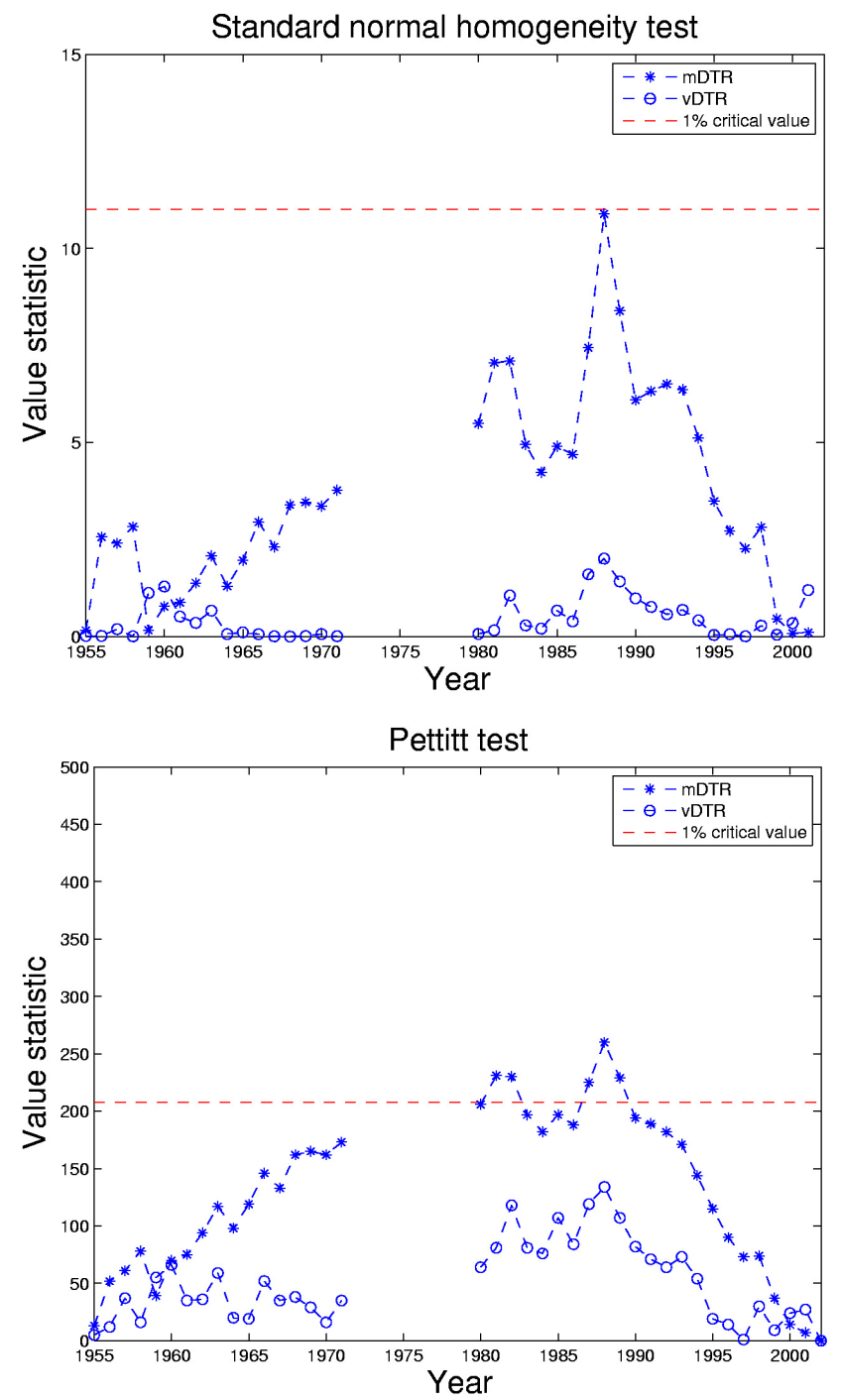

Figure 3. Results of the standard normal homogeneity test and Pettitt test applied to the 3 rural subseries (1955-2002, see Table 1).

did not exceed the $1 \%$ level, the null hypothesis of no breaks is not accepted by the Pettitt test for mDTR. This break point during the $80 \mathrm{~s}$ is also observed in the long time series of Uccle (not shown) and is probably due to the fact that the last two decades of the 20th century were marked by very high yearly average near-surface air temperatures in Belgium. The statistical analysis of the Uccle temperature data (www.climat.be) distinguishes four periods. Between 1833 and 1909 the yearly average near-surface air temperature was $8.8^{\circ} \mathrm{C}$. Between 1910 and 1942 and between 1943 and 1983 the yearly average near-surface air temperature amounted to respectively $9.5^{\circ} \mathrm{C}$ and $9.7^{\circ} \mathrm{C}$. From 1984 onwards, the yearly average is about $10.4^{\circ} \mathrm{C}$.

The values of the Von Neumann ratio test are 1.67 and 2.24 for mDTR and VDTR, respectively. The null hypothesis of no breaks is accepted when the test statistics is larger than the (a) Minimum near-surface air temperature

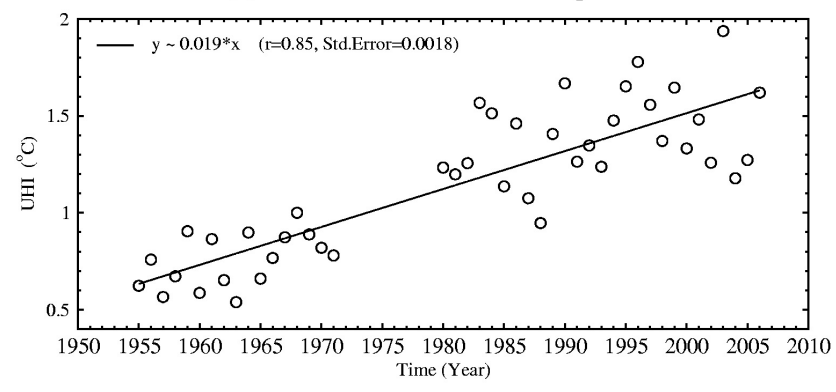

(b) Maximum near-surface air temperature

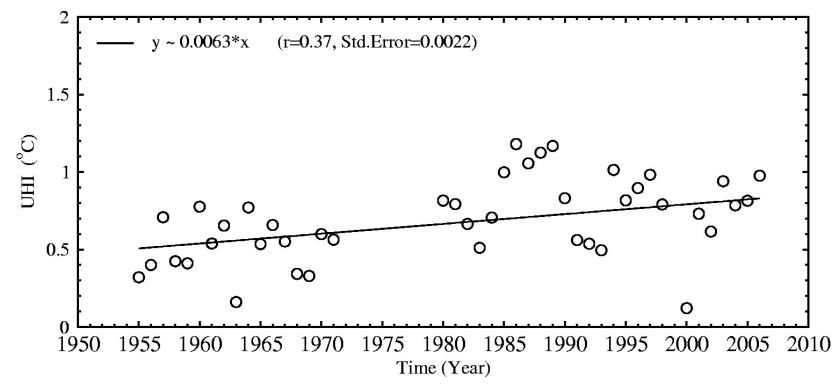

Figure 4. The summer-mean urban heat island (UHI) effect on (a) minimum and (b) maximum near-surface air temperature estimated as the difference between urban and rural ground-based weather stations, with the linear trend, 1955-2006. $r$ is the correlation coefficient and Std. Error is the standard error of the regression coefficient (no data were found between 1972 and 1979).

critical $1 \%$ value. For $n=40$, the critical value is 1.29 , which clearly indicates the homogeneity at the $1 \%$ level. Similarity, the Buishand range test indicates no homogeneity break in the series, the values are 1.62 and 0.85 for mDTR and vDTR, respectively. The null hypothesis of no breaks is accepted when the test statistics is lower than the critical $1 \%$ value. For $n=40$, the critical value is 1.74 , which clearly indicates the homogeneity at the $1 \%$ level. Since three tests accept the null hypothesis at the $1 \%$ level, the constructed reference rural series is assigned to class 1 "useful".

\subsubsection{Urban warming}

The UHI intensity is defined as the difference in near-surface air temperature between urban and rural stations. Estimates of urban bias at the Uccle recording station, on maximum and minimum near-surface air temperature, calculated during the summer of each year between 1955 and 2006, are plotted with the linear trends in Fig. 4 (unfortunately, no data were found between 1972 and 1979).

As indicated by Fig. 4, the UHI effect on minimum air temperature is shown to be rising at a higher rate $(2.85$ times more) than on maximum temperature, with a linear trend of $0.19^{\circ} \mathrm{C}\left( \pm 0.02{ }^{\circ} \mathrm{C}\right)$ and $0.06{ }^{\circ} \mathrm{C}\left( \pm 0.02{ }^{\circ} \mathrm{C}\right)(10 \mathrm{yr})^{-1}$, respectively. This result is consistent with previous work 
Table 2. Performance statistics for daily maximum $\left(T_{\max }\right)$ and minimum $\left(T_{\min }\right)$ near-surface air temperature, obtained from the "urban"

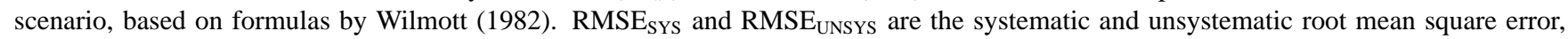
respectively.

\begin{tabular}{cccccc}
\hline & Correlation & Index of agreement & Bias $\left({ }^{\circ} \mathrm{C}\right)$ & RMSE $_{\text {SYS }}\left({ }^{\circ} \mathrm{C}\right)$ & RMSE $_{\text {UnSYS }}\left({ }^{\circ} \mathrm{C}\right)$ \\
\hline$T_{\max }$ & 0.96 & 0.97 & 1.12 & 1.38 & 2.33 \\
$T_{\min }$ & 0.96 & 0.97 & -0.43 & 0.66 & 1.89 \\
\hline
\end{tabular}

suggesting that the maximum air temperature is substantially less affected by urbanization than the minimum temperature (Landsberg, 1981; Karl et al., 1988; Kalnay and Cai, 2003; Hua et al., 2008). The increase of summer-mean urban bias on minimum temperature may be attributed to: (i) the higher thermal inertia, which, in combination with lower albedo of urban surfaces, delays the cooling of the cities at nights compared to rural areas (more explanation can be found in Hamdi and Schayes, 2008), (ii) to the limited evapotranspiration which prevents evaporative cooling of urban areas and (iii) during night hours, the contribution of anthropogenic heat can also influence long-term trend of near-surface air temperature.

\subsection{Urban warming from model simulations}

To isolate effects of urbanization on local near-surface climate conditions, we calculate the difference between two model integrations: (i) the "rural" scenario representing a hypothetical situation with no urban areas inside the Brussels Capital Region domain and (ii) the "urban" scenario, which represented the climate in the presence of urban areas using the measured historical changes of surface cover fractions. For this run, the surface cover fractions are updated each year using a linear interpolation. The use of the land surface model in an offline mode does not account for atmospheric feedback and therefore allows isolation of the effects of landscape difference on local near-surface climate conditions. The UHI effect is estimated as the difference between the "rural" and "urban" model integrations.

\subsubsection{Evaluation of the model}

To evaluate model performance, a comparison is made between the urban run and the routine observations of the Uccle ground station. Table 2 presents the statistics that quantify model performance for daily maximum $\left(T_{\max }\right)$ and minimum $\left(T_{\min }\right)$ air temperature using statistical measures (correlation coefficient, index of agreement, bias, and systematic and unsystematic root mean square error) based on formulas by Willmott (1982). The 2-m temperatures predicted by the urban run are consistent with meteorological observations, with a correlation coefficient of 0.96 and an index of agreement of 0.97 for $T_{\max }$ and $T_{\min }$. The systematic root mean

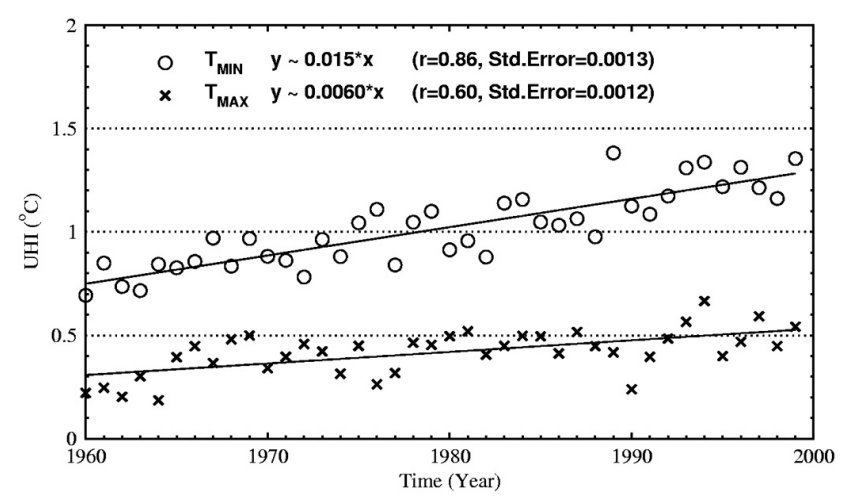

Figure 5. The summer-mean urban heat island (UHI) effect on minimum and maximum near-surface air temperature estimated as the difference between the "rural" and "urban" model integrations with the linear trend, 1960-1999. $r$ is the correlation coefficient and Std. Error is the standard error of the regression coefficient.

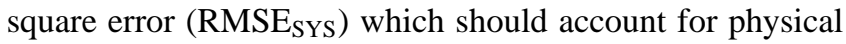
processes that the model does not routinely simulate well is small compared to the unsystematic root mean square error

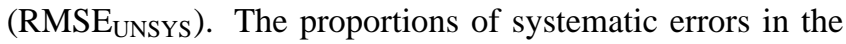
model are $26 \%$ and $11 \%$ for $T_{\max }$ and $T_{\min }$ respectively. The minimum temperature is better simulated by the model with a minor negative bias of $-0.43^{\circ} \mathrm{C}$ and $\mathrm{RMSE}_{\mathrm{SYS}}$ of $0.66^{\circ} \mathrm{C}$ against $1.12^{\circ} \mathrm{C}$ and $1.38^{\circ} \mathrm{C}$ for maximum temperature. More details about the results of simulations in both scenarios can be found in Hamdi et al. (2009).

\subsubsection{Urban warming}

Model simulations (see Fig. 5) show that the UHI effect on near-surface minimum temperature is rising at higher rate (2.5 times, observed 2.85 more) than on maximum temperature, with a linear trend of $0.15^{\circ} \mathrm{C}\left( \pm 0.01{ }^{\circ} \mathrm{C}\right)$ (observed $0.19^{\circ} \mathrm{C} \pm 0.02^{\circ} \mathrm{C}$ ) and $0.06^{\circ} \mathrm{C}\left( \pm 0.01^{\circ} \mathrm{C}\right.$ ) (observed $0.06^{\circ} \mathrm{C} \pm 0.02^{\circ} \mathrm{C}$ ) per decade, respectively. The summermean urban bias on the mean temperature $\left(T_{\text {mean }}=\left(T_{\text {min }}+\right.\right.$ $\left.T_{\max }\right) / 2$ ) at Uccle is $0.8^{\circ} \mathrm{C}$ (observed $0.9^{\circ} \mathrm{C}$ ). Based on 3$\mathrm{D}$ modeling approach using the ARPS model, Van Weverberg et al. (2008) found a somewhat higher value. They estimated the summer-mean urban bias at the Uccle station to be $1.13^{\circ} \mathrm{C}$. However, the authors used a very simple 
parameterization for representing urban land and the model runs were restricted to a few weather episodes given the large computational costs of simulations. Vandiepenbeeck (1998) applied another observational approach to assess the average UHI contribution between 1966 and 1995 . He studied the influence of urban heat advection on the near-surface air temperature time series of Uccle empirically by comparing the meteorological observation with those of a rural station far away from Brussels (St. Hubert, more than 100 km). He examined the dependence of the temperature differences on wind direction. He found the summer-mean urban heat contamination to be $0.8^{\circ} \mathrm{C}$ which is close to the value found in this study.

The modeling approach used in this study is able to capture all the observed characteristics of the urban warming even if:

1. We consider BCR as a lumped urban volume (no horizontal interactions). In fact, wind direction can exacerbate the urban signal (Zhang et al., 2009). However, since we are interested in climate, the urban effects corresponding to the sum of all weather events can be represented by a circle around the city and the urban effects gradually decrease toward the outskirts as it is found by the 3-D modeling study of Van Weverberg et al. (2008) for Brussels.

2. The entire BCR is composed of one homogeneous material comprising uniform thermophysical properties, irrespective of spatial variability. In this study, only one urban land use class is used and the geometrical, thermal, and radiative properties of roofs, walls, and roads were set to values representing a typical midsize European city (Hamdi et al., 2009).

3. Urbanization was assessed only by measuring changes of the impervious surface area (percent) in the BCR.

\section{Conclusions}

In this study, the urban heat island (UHI) effects on the nearsurface air temperature time series of Uccle during summer months was estimated using both ground-based weather stations and remote sensing imagery combined with a land surface scheme. The modeled estimate of urban warming was based on calculating the difference between two model integrations: (i) "the rural" scenario representing a hypothetical situation with no urban areas inside the Brussels Capital Region domain and the "urban" scenario, which represented the climate in the presence of urban areas using the measured changes of surface cover fractions. Results of our simulations is compatible with estimate of urban warming based on weather stations. However, exact compatibility is not to be expected because with the $10 \mathrm{~km}$ horizontal resolution of the climate drivers used to run the land surface scheme, we are not able to replicate the micrometeorology in the required detail.
This new technique combining data from remote sensing imagery and a land surface scheme presented in this study is a useful tool to estimate the urban heat island contamination in long time series, countering the drawbacks of an observational approach. It would be very simple and useful to applied this research method to other cities where credible rural ground weather stations do not exist. Furthermore, because of its local character, the results of this study will be particularly helpful for planners in developing scenarios for future land cover changes.

Acknowledgements. We thank S. Vanhuysse for providing us the data of the surface cover fraction. These data are obtained in the frame of the project 2008-02-AL. The authors are very grateful to G. Demarée for fruitful discussion about the history of weather stations and to two anonymous reviewers for comments that greatly improved the manuscript.

Edited by: M. Brunet-India

Reviewed by: two anonymous referees

\section{SC $\$$ The publication of this article is sponsored by the Swiss Academy of Sciences.}

\section{References}

ALADIN International Team: The ALADIN project: Mesoscale modelling seen as a basic tool for weather forecasting and atmospheric research, WMO Bull., 46, 317-324, 1997.

Demarée, G. R., Lachaert, P. J., Verhoeve, T., and Thoen, E.: The long-term daily central Belgium temperature (CBT) series (1767-1998) and early instrumental meteorological observations in Belgium, Climatic Change, 53, 269-293, 2002.

Fricke, R. and Wolff, E.: The MURBANDY project: development of land use and network databases for the Brussels area (Belgium) using remote sensing and aerial photography, Int. J. Appl. Earth Observ. Geoinform., 4, 33-50, 2002.

Fujibe, F.: Detection of urban warming in recent temperature trends in Japan, Int. J. Climatol., 29, 1811-1822, 2009.

Hamdi, R. and Masson, V.: Inclusion of a drag approach in the Town Energy Balance (TEB) scheme: offline 1-D evaluation in a street canyon, J. Appl. Meteor. Clim., 47, 2627-2644, 2008.

Hamdi, R. and Schayes, G.: Sensitivity study of the urban heat island intensity to urban characteristics, Int. J. Climatol., 28, 973982, 2008.

Hamdi, R., Deckmyn, A., Termonia, P., Demarée, G. R., Baguis, P., Vanhuysse, S., and Wolff, E.: Effects of historical urbanization in the Brussels Capital Region on surface air temperature time series: a model study, J. Appl. Meteorol. Clim., 48, 2181-2196, 2009.

Hua, L. J., Ma, Z. G., and Guo, W. D.: The impact of urbanization on air temperature across China, Theor. Appl. Climatol., 93, 179-194, 2008.

Huang, L., Lia, J., Zhaoa, D., and Zhub, J.: A fieldwork study on the diurnal changes of urban microclimate in four types of ground cover and urban heat island of Nanjing, China, Build. Environ., 43, 7-17, 2008. 
Institut National de Statistique: Chiffres provisoires de la population résidente au 1er janvier, par année 1990-2009, SPF Economie - Direction Générale Statistique et Information Economique, 2009.

Jones, P. D. and Lister, D. H.: The urban heat island in central London and urban-related warming trends in Central London since 1900, Weather, 64, 323-327, 2009.

Jones, P. D., Lister, D. H., and Li, Q.: Urbanization effects in largescale temperature records, with an emphasis on China, J. Geophys. Res., 113, D16122, doi:10.1029/2008JD009916, 2008.

Kalnay, E. and Cai, M.: Impact of urbanization and land use on climate change, Nature, 423, 528-531, 2003.

Karl, T. R., Diaz, H. F., and Kukla, G.: Urbanization: its detection and effect in the United States climate record, J. Climate, 1, 1099-1123, 1988.

Landsberg, H. E.: The urban climate, International Geophysics Series, 28, Academic Press, 275 pp., 1981.

Lemonsu, A., Grimmond, C. S. B., and Masson, V.: Modeling the surface energy balance of an old Mediterranean city core, J. Appl. Meteor., 43, 312-327, 2004.

Le Moigne, P.: SURFEX scientific documentation, Note de centre (CNRM/GMME), Météo-France, Toulouse, France, 211 pp., 2009.

Masson, V.: A physically-based scheme for the urban energy budget in atmospheric models, Bound.-Layer Meteor., 94, 357-397, 2000.

Masson, V. and Seity, Y.: Including atmospheric layers in vegetation and urban offline surface schemes, J. Appl. Meteor. Clim., 48, 1377-1397, 2009.

Masson, V., Grimmond, C. S. B., and Oke, T. R.: Evaluation of the Town Energy Balance (TEB) scheme with direct measurements from dry districts in two cities, J. Appl. Meteor., 41, 1011-1026, 2002.

Masson, V., Champeaux, J. L., Chauvin, F., Meriguet, C., and Lacaze, R.: A global database of land surface parameters at $1 \mathrm{~km}$ resolution in meteorological and climate models, J. Climate, 16, 1261-1282, 2003.

Noilhan, J. and Planton, S.: A simple parameterization of land surface processes for meteorological models, Mon. Wea. Rev., 117, 536-549, 1989.

Peterson, T. C., Daan, H., and Jones, P. D.: Initial selection of a GCOS surface network, Bull. Amer. Meteor. Soc., 78, 2145$2152,1997$.
Shouraseni, S. R. and Yuan, F.: Trends in extreme temperatures in relation to urbanization in twin cities metropolitan area, Minnesota, J. Appl. Meteor. Clim., 48, 669-679, 2009.

Uppala, S. M., Kallberg, P. W., Simmons, A. J., Andrae, U., da Costa Bechtold, V., Fiorino, M., Gibson, J. K., Haseler, J., Hernandez, A., Kelly, G. A., Li, X., Onogi, K., Saarinen, S., Sokka, N., Allan, R. P., Andersson, E., Arpe, K., Balmaseda, M. A., Beljaars, A. C. M., van de Berg, L., Bidlot, J., Bormann, N., Caires, S., Chevallier, F., Dethof, A., Dragosavac, M., Fisher, M., Fuentes, M., Hagemann, S., Holm, E., Hoskins, B. J., Isaksen, L., Janssen, P. A. E. M., Jenne, R., McNally, A. P., Mahfouf, J.-F., Morcrette, J.-J., Rayner, N. A., Saunders, R. W., Simon, P., Sterl, A., Trenberth, K. E., Untch, A., Vasiljevic, D., Viterbo, P., and Woollen, J.: The ERA-40 re-analysis, Q. J. Roy. Meteor. Soc., 131, 2961-3012, 2005.

Van de Vyver, H.: Evolution of extreme temperatures in Belgium since the 1950s, Theor. Appl. Climatol., submitted, 2010.

Vandiepenbeeck, M.: On a recent urban effect in the time series of the temperature in different stations in Belgium, Proc. Second European Conf. on Applied Climatology, Vienna, Austria, Österreichse Beiträge zu Meteorologie und Geophysik, CDROM, 19, 1998.

Vanhuysse, S., Depireux, J., and Wolff, E.: Etude de l'évolution de l'imperméabilisation du sol en région de Bruxelles-Capitale, Université Libre de Bruxelles, IGEAT, Brussels, Belgium, 60 pp., 2006.

Van Weverberg, K., De Ridder, K., and Van Rompaey, A.: Modeling the contribution of the Brussels Heat Island to a long temperature time series, J. Appl. Meteor. Clim., 47, 976-990, 2008.

Wijngaard, J. B., Klein Tank, A. M. G., and Können, G. P.: Homogeneity of the 20th century European daily temperature and precipitation series, Int. J. Climatol., 23, 679-692, 2003.

Wilmott, C. T.: Some comments on the evaluation of model performance, Bull. Amer. Meteor. Soc., 63, 1309-1313, 1982.

Yuan, F. and Bauer, M. E.: Comparison of impervious surface area and normalized difference vegetation index as indicators of surface urban heat island effects in Landsat imagery, Remote Sens. Environ., 106, 375-386, 2007.

Zhang, D. L., Shou, Y. X., and Dickerson, R. R.: Upstream urbanization exacerbates urban heat island effects, Geophys. Res. Lett., 36, L24401, doi:10.1029/2009GL041082, 2009. 